\title{
The Lens Opacities Classification System III grading in irradiated uveal melanomas to characterize proton induced cataracts
}

Short title: LOCS III grading for radiation induced cataracts

Thibaud MATHIS ${ }^{1}$, Laurence ROSIER ${ }^{2,}$ Fatima MENIAI $^{3}$, Stéphanie BAILLIF ${ }^{4}$, Celia MASCHI $^{4}$, Joël HERAULT ${ }^{5}$, Jean-Pierre CAUJOLLE ${ }^{4}$, Laurent KODJIKIAN ${ }^{1}$, Julia SALLERON $^{6}$, Juliette THARIAT $^{7}$

\section{Affiliations:}

1. Department of Ophthalmology, Croix-Rousse university hospital, Hospices Civils de Lyon, 69004 Lyon, France. UMR-CNRS 5510 Matéis, 69100 Villeurbane. France

2. Eye Clinic, Centre d'Exploration et de Traitement de la Retine et de la Macula, 33000

Bordeaux. France

3. Department of Radiation Oncology. Centre Oscar Lambret. 59000 Lille. France

4. Department of Ophthalmology. University Hospital Pasteur 2. Voie Romaine. 06189 Nice.

France

5. Department of Radiation Oncology- Proton therapy. 227 av de la Lanterne. 06200 Nice.

France

6. Department of Biostatistics, Institut de Cancérologie de Lorraine, 54500 Vandoeuvre les Nancy. France.

7. Department of Radiation Oncology. Centre Francois Baclesse / ARCHADE- Normandie Université. 3 Avenue du Général Harris. BP 5026. 14076 Caen. France

Corresponding Authors: Professor Juliette THARIAT

Department of Radiation Oncology

Centre François Baclesse / ARCHADE - Normandie Université

3 avenue du général Harris

BP 5026. 14076 CAEN Cedex 5, France

Tel.: + 33231455050

E-mail: jthariat@gmail.com

The authors and collaborators have neither conflict of interest nor financial disclosure

The study has received no funding

Key words: cataract; LOCS III; Lens Opacities Classification System III; grading; radiation therapy; proton therapy 


\section{INTRODUCTION}

Management of uveal melanomas is increasingly conservative, and proton beam therapy (PBT) and brachytherapy are the most frequently used techniques ${ }^{1,2}$. However, radiationinduced toxicities, such as optic neuropathy, retinopathy/maculopathy, dry eye syndrome, and cataracts can compromise vision ${ }^{3-5}$. As the lens is one of the most radiosensitive tissues among the ocular structures, cataracts are a frequent complication after ocular radiation therapy. Their incidence varies from $45 \%$ to $100 \%$ after ocular radiation therapy ${ }^{\mathbf{1 , 6}, \mathbf{7}}$. Radiation cataracts typically include posterior subcapsular lens clouding caused by damage to the subcapsular epithelium. However, there is neither absolute phenotypic conformity for the subtype of cataracts nor pathognomonic signs of radiation-induced cataracts. Senile, traumatic, or iatrogenic cataracts may also occur after radiation therapy. Full analysis of how exposure to therapeutic ionizing irradiation correlates and colocalizes with subsequent lens opacification is warranted to better establish causality. Such colocalization between radiation beam and opacities is only possible with specific forms of radiation modalities, in particular particle therapy that yields sharp dose distributions. Another important gap in current knowledge is that radiation cataracts are not graded like non-oncological cataracts ${ }^{7}$. The international Common Toxicity Criteria (CTC) classification does provide grades of severity in terms of visual acuity and cataracts but is not appropriate for uveal melanomas as it does not distinguish between vision loss due to maculopathy or cataracts, and does not describe lens opacities accurately. Depending on their location in the lens, opalescence, color and proportion of lens involved, lens opacifications can variably affect the vision. The international Lens Opacity Classification System (LOCS) defines a score based on the anatomic location and extent of cataracts on slit-lamp examination. The third version of the LOCS (LOCS III) is a robust and accurate means to classify cataracts as nuclear color, nuclear opalescence, cortical and posterior subcapsular cataracts, and grade them in terms of extent into the lens based on an atlas of standardized slit-lamp retroillumination images ${ }^{8}$. Assessing LOCS III in radiation-induced cataract could provide a better way to describe the effect of the proton beam on lens opacities.

This study was designed to evaluate the feasibility of using the LOCS III for radiationinduced cataracts and to examine correlations between the proton beam impact onto the lens and anatomical subtypes and extent of cataracts according to the LOCS III after PBT for uveal melanomas. 


\section{MATERIALS \& METHODS}

\section{Patient selection and cataract grading}

This interventional case series included consecutive patients with cataract from one hospital (Bordeaux, France) who underwent PBT for eye tumor between 2007 and 2016. Patients who already had cataracts or were pseudophakic prior to PBT, and patients who had intravitreal, subtenon or subconjunctival corticosteroid use were excluded from the study.

All included patients provided fully-informed consent before participation and an international review board approved the study (Ethics Committee of the French Society of Ophthalmology, IRB 00008855 Société Française d'Ophtalmologie IRB\#1).

Patients were evaluated for cataract development at a single ophthalmology hospital, expert in LOCS III grading (LR), after pupil dilation with $0.5 \%$ tropicamide and $10 \%$ phenylephrine hydrochloride 30 minutes before examination. A pupil diameter of more than $8 \mathrm{~mm}$ was considered as appropriately dilated for cataract evaluation. LOCS III grading scales include lens opacities defined as nuclear opalescence (NO), nuclear color (NC), cortical (C) and posterior subcapsular cataracts $(\mathrm{P})$ with six degrees of extent, i.e. severity. The LOCS III uses a set of six slit-lamp images of nuclear cataracts and five retro-illumination images of cortical or posterior subcapsular cataracts. Patient characteristics, tumor and cataract grading were prospectively recorded in a case report form (CRF), which was filled-out immediately after the medical appointment. Collected data included age, gender, initial and final visual acuity, and tumor characteristics (diagnosis, TNM staging, ultrasound thickness and diameter, volume, topography, and ciliary involvement).

\section{Treatment}

Irradiation was conducted with a $65 \mathrm{MeV}$ dedicated hospital-based cyclotron at the Cancer Center in Nice, France. Four tantalum fiducial markers were positioned under anesthesia onto the sclera using transillumination to define tumor borders. After surgery, topical corticosteroids were administered for two weeks. Tumor characteristics and associated signs were reported on ophthalmology reports based on transillumination, fundus (or retinography/angiography), ultrasound, and/or optical coherence tomography depending on tumor position relative to the equator of the eye. PBT was performed two to four weeks after fiducial placement. The Eyeplan treatment planning system software v1-3 was used. Ocular CT-scan with clips was performed for the delineation of normal structures and treatment plan optimization. The tumor was delineated and $2.5 \mathrm{~mm}$ lateral safety margins were added around the tumor. Beam modifiers were designed depending on the target range and lateral conformation was performed using a brass collimator adjusted to the tumor contours. The papilla, optic nerve, and macula were preserved whenever possible without compromising tumor control. In case of equatorial and pre-equatorial tumors, optimization using CT-scan modelling was performed on the anterior chamber with the lens as a surrogate. The lens was preserved whenever possible using adapted gaze, but not at the cost of tumor under coverage or sacrifice of optic nerve or macula. The patient's gaze was focused using a light-emitting diode located in a plane perpendicular to the beam. Proper projection of the beam using light field projection was systematically verified. Patient and tumor setup were controlled using online orthogonal X-ray images. Eye position was monitored using video camera surveillance during the 10-second treatment, eye movements triggering immediate beam interruption. The gaze direction was chosen to minimize the dose to the optic nerve and macula, and when possible the dose to the lens and retina. Each tumor was irradiated by four fractions of $13 \mathrm{~Gy}$ physical dose; the corresponding radiobiologically equivalent dose was 15 GyRBE that corresponds to the dose that would be given with conventional photon-based irradiation. 
Patients had antibiotic and corticosteroid eye drops for a period of one month after the end of treatment. All data concerning irradiation planning were collected in patient medical charts.

\section{Dose-volume analysis}

Lens periphery and lens core volumes were generated from the outer contours of the lens, which were delineated with a similar method throughout the study. Given the craniocaudal length of the lens and the CT-scan slice thickness, five slices were sufficient in all cases to delineate the lens on all slices where it was visible. The same two investigators (dosimetrists experts in the field) delineated patient lenses throughout the study. The treatment planning system for ocular PBT was able to reconstruct the lens volume, shape, and position to produce dose volume histograms, i.e. relationships between doses and volumes of the lens to be correlated with clinical outcomes such as cataracts. Computer-generated dose-volume histograms of the tumor and other structures (eyeball, ciliary body, etc.) were also extracted using the Eyeplan software. Graphic displays of treatment plans were analyzed for collimator aperture and isodose projections onto the eye. The volume of the eye lens and periphery lens that received at least $20 \%, 50 \%$, and $90 \%$ of the maximum prescription dose (52 Gy) defined as V10 Gy, V26 Gy, and V47 Gy, were calculated from full dose-volume histograms. Additionally, the volume of the ciliary body V10 Gy, V26 Gy, and V47 Gy was reported.

\section{Analysis of cataract subtypes according to the LOCS III}

All cataracts were graded by a single trained ophthalmologist (LR). Description of cataracts with slit-lamp examination was performed by an ophthalmologist blinded to lens irradiation avoidance on the proton therapy plan. We examined whether the proton beam anterior projection included the lens on graphic displays, and if so what proportion of lens was irradiated. We correlated the beam projection with grade of severity defined by the extent of the lens opacities after PBT. We then established whether the LOCS III location of cataracts were consistent with radiation damage, i.e. whether the classical anatomical subtype of cataracts, such as the posterior subcapsular subtype, was located within the beam projection. Similarly, we examined whether cataract subtypes atypical with respect to radiation-induced damage (nuclear for example) could be attributed to the proton beam in the terms of beam projection and location of opacities. Finally, we analyzed the extent of cataracts and correlated them with dose-volume histograms of the lens periphery or core volume.

\section{Statistical analysis}

The patient sample size was determined to evaluate the feasibility of integrating the LOCS III in patients with cataracts in a routine onco-ophthalmology practice with sufficient sampling of the various cataract subtypes. Visual acuity was converted to $\log$ MAR units for statistical investigations. Quantitative parameters were described by median and interquartile range (IQR) according to the normality of distributions assessed by the Shapiro-Wilk test. Qualitative parameters were described by frequency and percentage. For each of the four features of the lens (the extent of nuclear opalescence (NO), nuclear color (NC), cortical (C) and posterior subcapsular $(\mathrm{P})$ cataracts), the relationship between extent and patient characteristics was investigated using bivariate analyses. For binary parameters, the Wilcoxon test was used, and for qualitative with more than 3 levels the Kruskal-Wallis test was used. To test the relationship between the extent and quantitative parameters, the Spearman correlation coefficient was computed. When several patients or dose-volume characteristics were predictive of the extent with a significant level less than 0.1 , they were included in a multivariate linear model. The multicollinearity was assessed with the variance inflation factor (VIF) and parameters with a VIF $\geq 3$ were excluded. The stability of the final model was investigated with the bootstrap resampling method. The validity of the final model was 
checked by the Studentized residuals and Cook's distance. All analyses were performed using SAS 9.4 software (SAS Institute Inc., Cary, NC, USA). 


\section{RESULTS \\ Population}

Fifty-two patients were included. Patient characteristics are reported in Table 1. Melanoma types were choroidal $(75 \%)$, choroido-ciliary $(10 \%)$, ciliary $(8 \%)$, irido-ciliary $(5 \%)$, and iris $(2 \%)$. For choroidal melanomas, the anterior edge of tumor was posterior to the equator in 29 patients $(56 \%)$ and on the equator for six patients $(11 \%)$. None of the tumors were in contact with the lens at diagnosis and at the time of cataract grading. All patients were treated by PBT after tantalum fiducial placement and none of them had any complications related to this surgery.

\section{Cataract analyses according to the LOCS III}

The median time to diagnosis of cataracts after PBT was 36 months (22;83). Different subtypes of cataracts were graded accorded to the LOCS III at the slit lamp examination (Figure 1) and are reported in Figure 2. The crystalline lenses were outside or within the anterior projection of the proton beam in 10 patients (19\%) and 81 patients $(81 \%)$ of the patients, respectively. The proportion of lens in the proton beam projection was variable depending on tumor volume and location. This proportion exceeded $50 \%$ in 8 patients $(15 \%)$, was between $25 \%$ and $50 \%$ in $22(42 \%)$ patients and was less than $25 \%$ in 22 patients $(42 \%)$. The proportion of lens within the proton beam projection was significantly correlated with the extent of posterior subcapsular cataracts $(\mathrm{P})$ according to the LOCS III ( $\mathrm{p}=0.01$; Table 2)

\section{Cataracts according to the LOCS III and to clinical parameters}

No relationship was found between time to diagnosis and cataract subtype according to LOCS III grading. In bivariate analysis, a significant correlation was observed between tumor volume, maximum tumor diameter and the occurrence of posterior subcapsular cataracts $(\mathrm{P})$. The initial thickness of lens was not significantly associated with post-proton cataracts. Tumor stage was a significant predictive factor for the extent of subcapsular cataracts $(\mathrm{P})$ according to the LOCS III; T3 stage was significantly associated with the extent of posterior subcapsular cataracts $(\mathrm{P})(\mathrm{p}<0.01)$. There was no significant correlation between tumor type (iris, ciliary body or choroidal melanoma) and cataract subtype. However, for choroidal melanomas, an equatorial tumor correlated with the extent (grade of LOCS III severity) of posterior subcapsular cataracts $(\mathrm{P})(\mathrm{p}<0.01)$ (Table 3).

After a multivariate analysis, tumor volume $(\mathrm{p}<0.01)$ and an equatorial tumor location $(p=0.01)$ were found to be independently associated with the occurrence of posterior subcapsular cataracts $(\mathrm{P})$.

\section{Cataracts according to the LOCS III and dose-volume parameters in patients with an irradiated lens}

Focusing on the 42 patients whose crystalline lens was at least partially in the proton field, dose-volume characteristics are described in Table 4. The extent/severity of posterior subcapsular (P) and nuclear color cataracts (NC) were significantly correlated with the volume of ciliary body receiving $10 \mathrm{~Gy}$ and $26 \mathrm{~Gy}$, which corresponded to $20 \%, 50 \%$ of the maximum prescribed dose. Thus, the higher the dose to the ciliary body, the more severe the subcapsular (P) and nuclear color (NC) cataracts. Dose to the ciliary body was not significantly correlated with other subtypes of cataracts (NO and C) ( $p>0.05)$. In addition, it was observed that the extent of posterior subcapsular cataracts $(\mathrm{P})$ was significantly correlated with the proportion of lens periphery receiving at least $10 \mathrm{~Gy}, 26 \mathrm{~Gy}$, and $47 \mathrm{~Gy}$. The larger the volume of lens irradiated the more severe the posterior subcapsular cataracts. After adjusting the results of dose-volume parameters on tumor volume and a posterior tumor location, the volume of lens receiving $10 \mathrm{~Gy}$ and 26 Gy remained significantly associated 
with the extent/severity of posterior subcapsular (respectively, $\mathrm{p}=0.04$ and $\mathrm{p}=0.03$ ). The other parameters were no longer significantly associated after adjustment: volume of ciliary body receiving $10 \mathrm{~Gy}(\mathrm{p}=0.09)$, that receiving $26 \mathrm{~Gy}(\mathrm{p}=0.06)$, the volume of lens periphery receiving $10 \mathrm{~Gy}(\mathrm{p}=0.07)$, that receiving $26 \mathrm{~Gy}(\mathrm{p}=0.053)$, and the volume of lens receiving $47 \mathrm{~Gy}(\mathrm{p}=0.13)$. No stable multivariate model was found for the extent/severity of nuclear color (NC) cataracts due to strong collinearity. 


\section{DISCUSSION}

Ocular proton therapy using a dedicated ocular cyclotron has physical properties that allow a lens-sparing approach owing to more accurate dose distribution, and which are not found in other photon-based modalities. This is due to a small lateral penumbra to the order of one millimeter or less at the radiation field edges. Radiation-induced cataracts were first described in $1952^{9}$. Until very recently, the threshold for detectable lens opacities was assumed to be to the order of $2 \mathrm{~Gy}$ (with conventional X-ray photon irradiation) for acute exposure to ionizing radiation and 5 Gy for highly fractionated or protracted, chronic, exposure ${ }^{10}$; for visionimpairing cataracts, these thresholds were to the order of $5 \mathrm{~Gy}{ }^{10}$. More recent

epidemiological studies have demonstrated that doses of conventional radiation therapy to the order of 1 Gy can lead to detectable lens opacities ${ }^{11,12}$. Several other radiation-related factors have been involved in the occurrence of radiation cataracts, such as the type of irradiation, total dose, dose per fraction, and time since exposure. Although, with PBT, lens irradiation was completely avoided in about a fifth of the 52 consecutive patients included in the present study, all patients had cataracts per study selection criteria. Despite the possibility to avoid lens irradiation with PBT for uveal melanomas, radiation-induced cataracts are, however, frequent as there are numerous situations where the lens is next to the tumor or within the anterior projection of the proton beam. Similar results have also been reported in other series of uveal melanoma patients after PBT ${ }^{7,13,14}$. In this cohort, all patients were treated uniformly with a similar method, total prescription dose, and lens-sparing approach.

The LOCS III has been validated in both clinical and epidemiological studies of cataracts of various origins ${ }^{8,15,16}$ but is not commonly used in ocular oncology. We showed herein the feasibility of using the LOCS III to evaluate cataracts after PBT for uveal melanomas. In particular, we found correlations between the proton beam projection and the anatomical location of the lens opacities, i.e. LOCS III subtypes NC, NO, C, and P. We also found relationships between the volume of lens included in the proton field and extent of lens opacities as defined by the LOCS III severity. It was beyond the scope of the current study to correlate cataract severity and the deterioration of the visual acuity after PBT owing to major confounding factors such as radiation maculopathy and optic neuropathy, which, contrary to cataracts, are often irreversible ${ }^{17}$. Additionally, the patient sample size was neither designed to assess the influence of ocular radiation side effects nor to show the importance of wellknown confounding factors (age, diabetes, etc...) on visual acuity. However, to the best of our knowledge, this is the only study that assessed correlations between accurate characteristics of cataracts using the LOCS III and the ballistics of the proton beam taking advantage of its excellent lateral dose distribution. We showed that cataracts were diagnosed at a median 36 months post treatment, which is earlier than with more fractionated dose regimens ${ }^{18}$ but consistent with other hypofractionated high-dose proton therapy series ${ }^{19}$.

Radiation-induced cataracts are typically reported to be of subcapsular type ${ }^{20,21}$. Pathogenesis suggests that radiation damages the DNA of proliferative cells that will migrate posteriorly leading to deformed lens fiber and debris accumulation in the subcapsular regions, especially posteriorly ${ }^{22}$. However, we did not exclusively observe posterior subcapsular cataract, which is consistent with a study investigating brachytherapy that found that among the $85 \%$ of anterior ocular tumor patients who had cataracts, only $52 \%$ were of subcapsular type but no detailed description of plaque placement and type/severity of cataracts was reported ${ }^{23}$. This observation highlights the complexity of the mechanisms involved in post-radiation cataracts. Moreover, we cannot exclude that so-called radiation-induced cataracts may indeed be due to classical confounding factors but also other iatrogenic causes (traumatic cataracts by tumor compression or during clip placement, use of topical steroids, etc...). Furthermore, it is 
unlikely that the small dose received by secondary neutrons contributed to cataracts ${ }^{18,19}$ but bystander effects on cells that are not directly irradiated but are at short distances from irradiated cells and communicate between each other by means of intercellular junctions or cytokines ${ }^{20}$ is possible.

Among the 42 patients with an irradiated lens, the proportion of lens in the proton beam was significantly correlated with the occurrence of posterior subcapsular cataracts $(\mathrm{P})$ according to the LOCS III. In addition, the extent of posterior subcapsular (P) and nuclear color (NC) cataracts was also significantly correlated with the dose to the ciliary body. Ciliary body involvement of the tumor or close proximity between the tumor and ciliary body can result in radiation damage to the ciliary body. Such damage may result in intra-ocular inflammation and secondary posterior subcapsular cataracts, as already reported ${ }^{21}$. Because ciliary body melanomas are anterior tumors in close proximity with the lens, gazing angle cannot be fully optimized to entirely avoid the lens and to exclude the lens nucleus from the proton beam projection. Moreover, ciliary body melanomas are peripheral tumors that are generally thicker than posterior or equatorial tumors as they are diagnosed later and thus require higher dose. For these reasons, lens exclusion from the proton beam projection can rarely be done in such localizations.

We also observed that posterior tumor location was significantly correlated with the appearance of posterior subcapsular cataracts. This may be due to the fact that when tumors are very close to the posterior structures, treatment plan optimization is performed to spare the macula/optic disk rather than the lens.

While we did not find any correlation between uveal melanoma types treated (choroidal, iris, or ciliary body involvement) and LOCS III subtype, we observed a significant correlation between T3 stage and the occurrence of posterior subcapsular (P) cataracts. This finding may be a consequence of the volume of tumor and lens irradiated but also of inflammation associated with significant tumor necrosis as well as vessel damage in the treated eyes ${ }^{24}$. Kleineidam et al. also reported thickness and the anterior tumor location as prognostic factors of cataractogenesis after Cobalt 60 brachytherapy of 370 uveal melanomas ${ }^{25}$. However, use of corticosteroids to control intraocular inflammation was not reported ${ }^{25}$ but prolonged use of these drugs is required to induce cataracts.

With respect to study limitations, the lack of controls was intrinsic to the study selection criteria as the aim of the current study was to correlate the subtype of cataracts according to LOCS III with the projection of the proton beam onto the crystalline lens and the proportion of lens within the proton field. The small number of cataract subtypes may be considered as a weakness; however, this longitudinal cohort was designed to assess the feasibility of using the LOCS III in oncology.

The design of the study was not appropriate to eliminate confounding factors for cataract development ${ }^{26}$. For instance, examination of the healthy eye would have been useful in identifying cases of bilateral cataracts that are characteristic of senile or diabetic cataracts, but it is unlikely that these would have developed within 36 months, and this relatively rapid occurrence is more consistent with high-dose radiation-induced cataracts. ${ }^{7,25,27-29}$ In addition, the patients included herein are unlikely to have been affected by steroid-induced cataracts because of the relatively short prescription of corticosteroids after surgery for fiducial placement is not sufficient to induce cataracts ${ }^{27,30}$. Another potential limitation is that interobserver variability in the slit-lamp evaluation of cataracts may have led to interpretation bias, especially when evaluating the opalescence of the nucleus and severity score. However, the 
current study was designed to assess cataracts according to the LOCS III by a single ophthalmologist trained in the use of LOCS III for non-oncological cataracts.

Based on the present study, the LOCS III is of potential interest to better characterize and understand the mechanisms of radiation-induced cataracts. These initial findings need further validation in larger prospective cohort studies, and this could lead in the future to promote the use of lens-sparring techniques when possible ${ }^{27}$. The radiation oncology community currently lacks recommendations for dose thresholds to be applied to the lens in therapeutic conditions using high total dose, high dose rate, and hypofractionation. Moreover, there is currently usually no distinction made between the different parts of the lens during PBT planning. Knowing correlations between visual impairment and location of opacifications might be used to optimize fixation angle and beam shaping when such change in planning is neither a risk for tumor coverage or macula and optic disc sparing. Using LOCS III may even be more relevant to new PBT modalities than passive delivery such as used in the current study and in most international reference centers. Active scanning is the method used in a few but expanding number of new PBT facilities, and it can achieve a slightly better dose sparing at beam entry and thus may allow more personalized lens-sparing based on LOCS III grading. Of note, however, such facilities still require adaptations (including energy optimization and lateral collimation) to achieve correct depth dose distribution (tumor and posterior structures). Confirmation of the correlation between visual impairment and the severity of cataracts assessed by the LOCS III ${ }^{31,32}$ in an oncology context could also be of great interest in eyes where other radiation complications may occur in view of a potential cataract surgery. More systematic use of the LOCS III in onco-ophthalmology should probably be encouraged.

\section{CONCLUSION}

We have shown herein the feasibility of LOCS III grading for radiation cataracts. We also showed that there was a correlation between dose to the lens and occurrence not only of posterior subcapsular cataracts subtype $(\mathrm{P})$ but also of nuclear color cataracts $(\mathrm{NC})$, and report that extent/severity of posterior subcapsular $(\mathrm{P})$ correlated with irradiated lens volume. Better knowledge of correlations between LOCS III and lens dose-volume effects may help to personalize PBT planning, not only with current modalities of delivering PBT but possibly even more with PBT facilities using active scanning (pending some adaptations of equipment used for eye treatment). Prospective studies using the LOCS III are needed to better address the subtype and severity of cataracts in oncology, and to define thresholds for surgery. Better characterization of cataracts after irradiation might also help to further fill gaps in current knowledge of the mechanisms of radiation induced cataracts. 


\section{ACKNOWLEDGMENTS:}

a. Funding/Support: None.

b. Financial disclosures: T. Mathis is a consultant for Allergan, Bayer and Novartis; L. Kodjikian is a consultant for Alcon, Alimera, Allergan, Bayer, Novartis and Théa; The following authors have no financial disclosures: L. Rosier, F. Meniai, S. Baillif, J. Herault, JP. Caujolle, J. Salleron and J. Thariat

c. Other acknowledgments: The authors thank Dr Philip Robinson (Direction de la Recherche Clinique et de l'Innovation, Hospices Civils de Lyon) for proofreading and critical review of the manuscript, and Dr Arthur Handaye-Dessus for data analysis. 


\section{REFERENCES}

1. Collaborative Ocular Melanoma Study Group. Incidence of cataract and outcomes after cataract surgery in the first 5 years after iodine 125 brachytherapy in the Collaborative Ocular Melanoma Study: COMS Report No. 27. Ophthalmology. 2007;114(7):1363-1371.

2. Mathis T, Cassoux N, Tardy M, et al. [Management of uveal melanomas, guidelines for oncologists]. Bull Cancer. 2018;105(10):967-980.

3. Bensoussan E, Thariat J, Maschi C, et al. Outcomes After Proton Beam Therapy for Large Choroidal Melanomas in 492 Patients. Am J Ophthalmol. 2016;165:78-87.

4. Thariat J, Grange J-D, Mosci C, et al. Visual Outcomes of Parapapillary Uveal Melanomas Following Proton Beam Therapy. Int J Radiat Oncol Biol Phys. 2016;95(1):328335.

5. Thariat J, Maschi C, Lanteri S, et al. Dry Eye Syndrome After Proton Therapy of Ocular Melanomas. Int J Radiat Oncol Biol Phys. 2017;98(1):142-151.

6. Finger PT. Tumour location affects the incidence of cataract and retinopathy after ophthalmic plaque radiation therapy. Br J Ophthalmol. 2000;84(9):1068-1070.

7. Seibel I, Cordini D, Hager A, et al. Cataract development in patients treated with proton beam therapy for uveal melanoma. Graefes Arch Clin Exp Ophthalmol Albrecht Von Graefes Arch Klin Exp Ophthalmol. 2016;254(8):1625-1630.

8. Chylack LT, Wolfe JK, Singer DM, et al. The Lens Opacities Classification System III. The Longitudinal Study of Cataract Study Group. Arch Ophthalmol. 1993;111(6):831836.

9. Cogan DG, Donaldson DD, Reese AB. Clinical and pathological characteristics of radiation cataract. AMA Arch Ophthalmol. 1952;47(1):55-70.

10. Merriam GR, Focht EF. A clinical and experimental study of the effect of single and divided doses of radiation on cataract production. Trans Am Ophthalmol Soc. 1962;60:35-52. 11. Ainsbury EA, Barnard S, Bright $S$, et al. Ionizing radiation induced cataracts: Recent biological and mechanistic developments and perspectives for future research. Mutat Res. 2016;770(Pt B):238-261.

12. Bouffler S, Ainsbury E, Gilvin P, Harrison J. Radiation-induced cataracts: the Health Protection Agency's response to the ICRP statement on tissue reactions and recommendation on the dose limit for the eye lens. J Radiol Prot Off J Soc Radiol Prot. 2012;32(4):479-488.

13. Conway RM, Poothullil AM, Daftari IK, Weinberg V, Chung JE, O'Brien JM.

Estimates of ocular and visual retention following treatment of extra-large uveal melanomas by proton beam radiotherapy. Arch Ophthalmol. 2006;124(6):838-843.

14. Riechardt AI, Cordini D, Willerding GD, et al. Proton beam therapy of parapapillary choroidal melanoma. Am J Ophthalmol. 2014;157(6):1258-1265.

15. Tang Y, Wang X, Wang J, et al. Prevalence of Age-Related Cataract and Cataract Surgery in a Chinese Adult Population: The Taizhou Eye Study. Invest Ophthalmol Vis Sci. 2016;57(3):1193-1200.

16. Gali HE, Sella R, Afshari NA. Cataract grading systems: a review of past and present. Curr Opin Ophthalmol. 2019;30(1):13-18.

17. Gragoudas ES, Egan KM, Arrigg PG, Seddon JM, Glynn RJ, Munzenrider JE. Cataract extraction after proton beam irradiation for malignant melanoma of the eye. Arch Ophthalmol. 1992;110(4):475-479.

18. Carnicer A, Letellier V, Rucka G, Angellier G, Sauerwein W, Herault J. Study of the secondary neutral radiation in proton therapy: toward an indirect in vivo dosimetry. Med Phys. 2012;39(12):7303-7316.

19. Carnicer A, Letellier V, Rucka G, Angellier G, Sauerwein W, Hérault J. An indirect in vivo dosimetry system for ocular proton therapy. Radiat Prot Dosimetry. 2014;161(1-4):373376. 
20. Hamada N, Matsumoto H, Hara T, Kobayashi Y. Intercellular and intracellular signaling pathways mediating ionizing radiation-induced bystander effects. $J$ Radiat Res. 2007;48(2):87-95.

21. Gragoudas ES, Egan KM, Walsh SM, Regan S, Munzenrider JE, Taratuta V. Lens changes after proton beam irradiation for uveal melanoma. Am J Ophthalmol. 1995;119(2):157-164.

22. Merriam GR, Worgul BV. Experimental radiation cataract--its clinical relevance. Bull N Y Acad Med. 1983;59(4):372-392.

23. Finger PT, Chin KJ, Yu G-P, Patel NS, Palladium-103 for Choroidal Melanoma Study Group. Risk factors for cataract after palladium-103 ophthalmic plaque radiation therapy. Int J Radiat Oncol Biol Phys. 2011;80(3):800-806.

24. Saornil MA, Egan KM, Gragoudas ES, Seddon JM, Walsh SM, Albert DM. Histopathology of proton beam-irradiated vs enucleated uveal melanomas. Arch Ophthalmol. 1992;110(8):1112-1118.

25. Kleineidam M, Augsburger JJ, Hernandez C, Glennon P, Brady LW. Cataractogenesis after Cobalt-60 eye plaque radiotherapy. Int J Radiat Oncol Biol Phys. 1993;26(4):625-630.

26. Miglior S, Marighi PE, Musicco M, Balestreri C, Nicolosi A, Orzalesi N. Risk factors for cortical, nuclear, posterior subcapsular and mixed cataract: a case-control study. Ophthalmic Epidemiol. 1994;1(2):93-105.

27. Thariat J, Jacob S, Caujolle J-P, et al. Cataract Avoidance With Proton Therapy in Ocular Melanomas. Invest Ophthalmol Vis Sci. 2017;58(12):5378-5386.

28. Thariat J, Racadot S, Pointreau Y, et al. [Intensity-modulated radiotherapy of head and neck cancers: Dose effects on the ocular, orbital and eyelid structures]. Cancer Radiother. 2016;20(6-7):467-474.

29. Thariat J, Rahmi A, Salleron J, et al. Proton Beam Therapy for Iris Melanomas in 107 Patients. Ophthalmology. 2018;125(4):606-614.

30. Urban RC, Cotlier E. Corticosteroid-induced cataracts. Surv Ophthalmol. 1986;31(2):102-110.

31. Grewal DS, Brar GS, Grewal SPS. Correlation of nuclear cataract lens density using Scheimpflug images with Lens Opacities Classification System III and visual function. Ophthalmology. 2009;116(8):1436-1443.

32. Pan A-P, Wang Q-M, Huang F, Huang J-H, Bao F-J, Yu A-Y. Correlation among lens opacities classification system III grading, visual function index-14, pentacam nucleus staging, and objective scatter index for cataract assessment. Am J Ophthalmol.

2015;159(2):241-247.e2. 


\section{FIGURE CAPTIONS}

Figure 1: Cataract grading according to the LOCS III at 3 years after proton beam therapy for choroidal melanoma. NO 0, NC 1, C 0, P 3.

$N O$ : nuclear opalescence, $N C$ : nuclear color, $C$ : cortical, $P$ : posterior subcapsular cataracts.

Figure 2: Cataract extent and anatomical location according to the LOCS III in 52 patients The $\mathrm{X}$ axis corresponds to the cataract score according to the LOCS III.

The $\mathrm{Y}$ axis corresponds to the frequency of the different cataract subtypes observed in the study population.

$N O$ : nuclear opalescence, $N C$ : nuclear color, $C$ : cortical, $P$ : posterior subcapsular cataracts. 


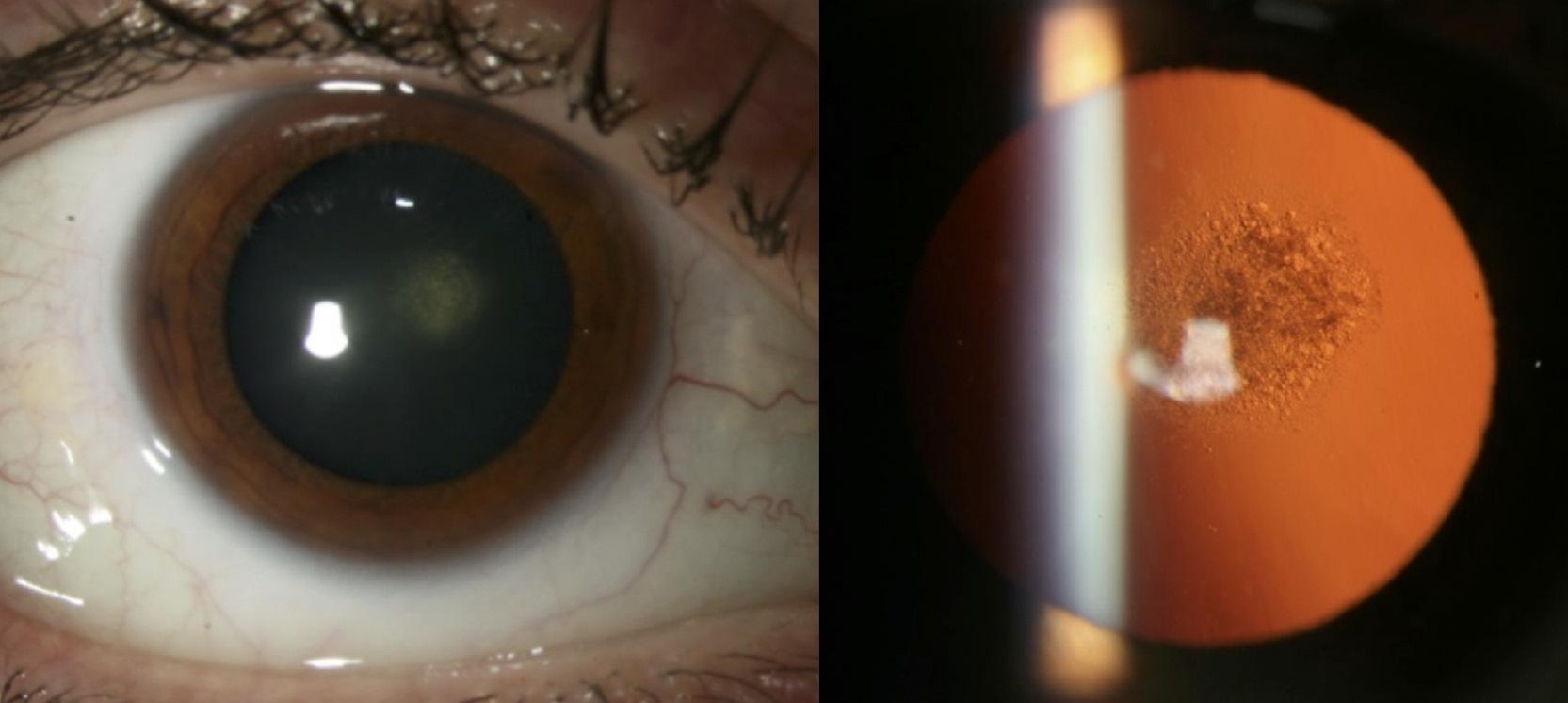




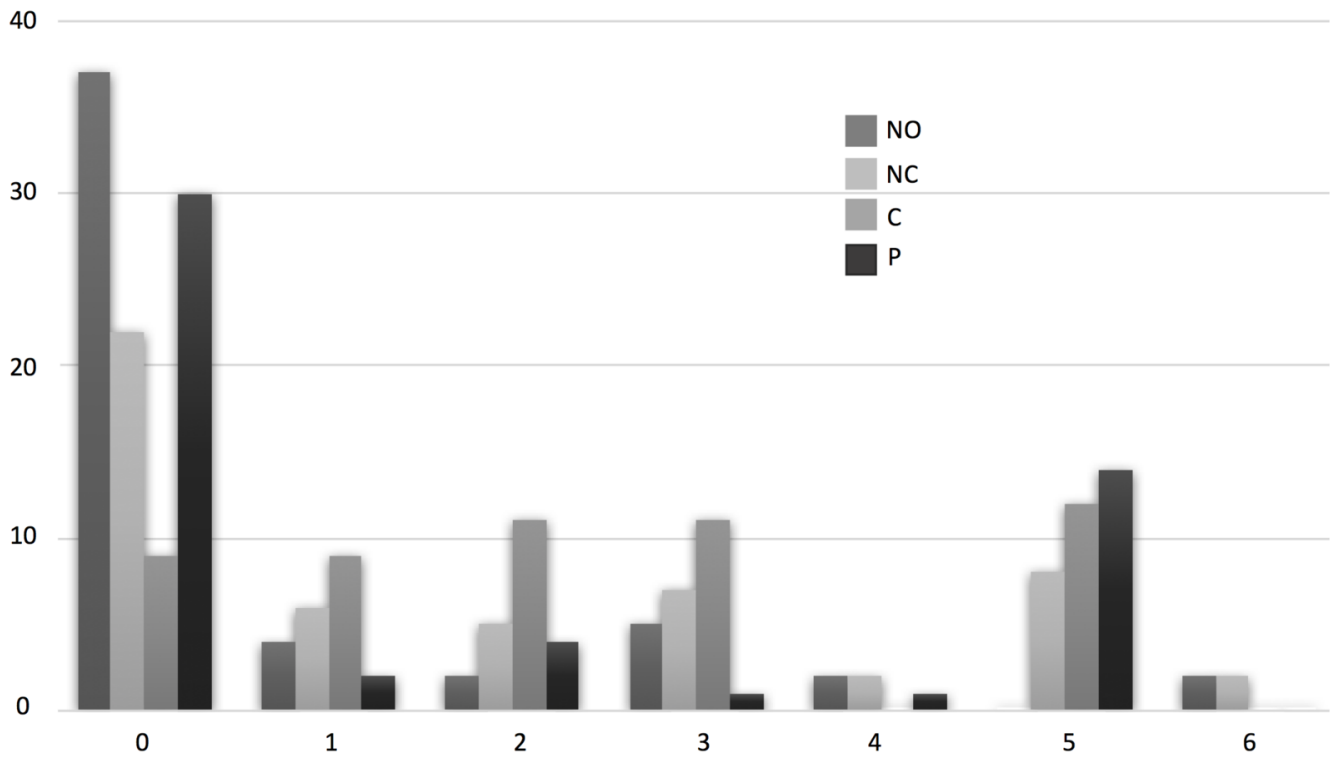


Table 1: Patient and tumor characteristics

\begin{tabular}{|c|c|}
\hline Patient characteristics & \\
\hline Median age in years $(I Q R)$ & $65(57 ; 71)$ \\
\hline Gender, $\%(n)$ & \\
\hline - $\quad$ Female & $52 \%(27)$ \\
\hline - $\quad$ Male & $48 \%(25)$ \\
\hline Diabetes mellitus, \% (n) & $15 \%(8)$ \\
\hline Lens thickness (mm), median (IQR) & $4.5(4 ; 5)$ \\
\hline Initial visual acuity, median $(I Q R)$ & $0.95(0.10-1.00)$ \\
\hline Final visual acuity, median $(I Q R)$ & $0.5(0.01-1.00)$ \\
\hline Tumor characteristics & \\
\hline Melanoma type, $\%(n)$ & \\
\hline - $\quad$ Choroidal melanoma & $75 \%(39)$ \\
\hline - $\quad$ Ciliary body melanoma & $8 \%(4)$ \\
\hline - $\quad$ Irido-ciliary melanoma & $5 \%(3)$ \\
\hline - $\quad$ Choroido-ciliary melanoma & $10 \%(5)$ \\
\hline - $\quad$ Iris Melanoma & $2 \%(1)$ \\
\hline UICC staging, $\%(n)$ & \\
\hline - $\quad \mathrm{T} 2 \mathrm{a}$ & $69 \%(36)$ \\
\hline - $\quad \mathrm{T} 3$ & $31 \%(16)$ \\
\hline Tumor diameter (mm), median (IQR) & $13.4(11.25 ; 16.9)$ \\
\hline Tumor volume $\left(\mathrm{cm}^{3}\right)$, median $(I Q R)$ & $0.34(0.17 ; 0.79)$ \\
\hline Tumor topography, \% (n) & \\
\hline - $\quad$ Anterior & $33 \%(17)$ \\
\hline - $\quad$ Equatorial & $11 \%(6)$ \\
\hline - $\quad$ Posterior & $56 \%(29)$ \\
\hline $\begin{array}{l}\text { Ciliary body involvement, } \%(n) \\
\text { - } \quad \text { Yes } \\
\text { - } \quad \text { No }\end{array}$ & $\begin{array}{l}31 \%(16) \\
69 \%(36)\end{array}$ \\
\hline
\end{tabular}

$I Q R$, interquartile range 
Table 2: Extent of LOCS III cataract types according to the proportion of lens within the proton beam projection in bivariate analysis in 52 patients

\begin{tabular}{|l|c|c|c|c|}
\hline & NO & NC & C & P \\
\hline $\begin{array}{l}\text { Proportion of lens } \\
\text { within proton beam } \\
\text { projection }\end{array}$ & $-0.21^{*}$ & $0.27 *$ & $0.22^{*}$ & $0.34^{*}$ \\
$\mathbf{p}=0.13$ & $\mathrm{p}=0.06$ & $\mathrm{p}=0.12$ & $\mathbf{p = 0 . 0 1}$ \\
\hline
\end{tabular}

*Results presented with Spearman correlation coefficient

No: nuclear opalescence, $N C$ : nuclear color, $C$ : cortical, $P$ : posterior subcapsular cataracts. 
Table 3: Prognostic factors of cataract extent according to the LOCS III in bivariate analysis in the 52 patients

\begin{tabular}{|c|c|c|c|c|}
\hline & \multicolumn{4}{|c|}{ Cataract subtype according to LOCS III } \\
\hline & NO & $N C$ & $C$ & $P$ \\
\hline Time to diagnosis ${ }^{1}$ & $\begin{array}{c}0.07 \\
\mathrm{p}=0.58\end{array}$ & $\begin{array}{c}-0.03 \\
p=0.78\end{array}$ & $\begin{array}{c}0.18 \\
p=0.19\end{array}$ & $\begin{array}{c}0.015 \\
\mathrm{p}=0.91\end{array}$ \\
\hline $\operatorname{Age}^{1}$ (years) & $\begin{array}{c}0.20 \\
p=0.15\end{array}$ & $\begin{array}{c}0.26 \\
p=0.05\end{array}$ & $\begin{array}{c}0.22 \\
p=0.11\end{array}$ & $\begin{array}{c}0.01 \\
p=0.89\end{array}$ \\
\hline Thickness of lens ${ }^{1}$ & $\begin{array}{c}0.17 \\
p=0.21\end{array}$ & $\begin{array}{c}0.04 \\
p=0.76\end{array}$ & $\begin{array}{c}0.06 \\
p=0.64\end{array}$ & $\begin{array}{c}-0.06 \\
p=0.67\end{array}$ \\
\hline Tumor volume ${ }^{1}$ & $\begin{array}{c}-0.28 \\
\mathbf{p}=\mathbf{0 . 0 3}\end{array}$ & $\begin{array}{c}0.18 \\
p=0.19\end{array}$ & $\begin{array}{c}0.007 \\
p=0.95\end{array}$ & $\begin{array}{c}0.47 \\
\mathbf{p}<\mathbf{0 . 0 1}\end{array}$ \\
\hline Maximum tumor diameter $^{1}$ & $\begin{array}{c}-0.26 \\
p=0.06\end{array}$ & $\begin{array}{c}0.15 \\
p=0.27\end{array}$ & $\begin{array}{c}-0.08 \\
p=0.52\end{array}$ & $\begin{array}{c}0.35 \\
\mathbf{p}<\mathbf{0 . 0 1}\end{array}$ \\
\hline $\begin{array}{l}\text { UICC }^{\text {stage }} \mathbf{2}^{2} \\
\text { T2a }(n=36) \\
\text { T3 }(n=16)\end{array}$ & $\begin{array}{c}0(0 ; 1.5) \\
0(0 ; 0) \\
p=0.37\end{array}$ & $\begin{array}{c}1(0 ; 3) \\
2.5(0 ; 5) \\
p=0.22\end{array}$ & $\begin{array}{c}2(1 ; 3) \\
1.5(0 ; 5) \\
\mathrm{p}=0.73\end{array}$ & $\begin{array}{l}0(0 ; 1.5) \\
4.5(0 ; 5) \\
\mathbf{p}<\mathbf{0 . 0 1}\end{array}$ \\
\hline $\begin{array}{l}\text { Tumor type }^{2} \\
\text { Choroidal melanoma }(n=39) \\
\text { Other }(n=13)\end{array}$ & $\begin{array}{l}0(0 ; 1) \\
0(0 ; 0) \\
\mathrm{p}=0.61\end{array}$ & $\begin{array}{c}2(0 ; 4) \\
1(02) \\
\mathrm{p}=0.35\end{array}$ & $\begin{array}{l}2(1 ; 5) \\
2(1 ; 3) \\
\mathrm{p}=0.52\end{array}$ & $\begin{array}{l}0(0 ; 5) \\
0(0 ; 0) \\
p=0.15\end{array}$ \\
\hline $\begin{array}{l}\text { Tumor location }{ }^{2} \text { with respect to ocular } \\
\text { equator (for choroidal melanoma only) } \\
\text { Anterior } \\
\text { Equatorial } \\
\text { Posterior }\end{array}$ & $\begin{array}{l}0(0 ; 1) \\
0(0 ; 0) \\
0(0 ; 1) \\
p=0.73\end{array}$ & $\begin{array}{c}2(1 ; 3) \\
2.5(0 ; 5) \\
2(0 ; 3) \\
\mathrm{p}=0.76\end{array}$ & $\begin{array}{l}2(1 ; 3) \\
5(0 ; 5) \\
2(1 ; 3) \\
\mathrm{p}=0.54\end{array}$ & $\begin{array}{l}0(0 ; 4) \\
5(3 ; 5) \\
0(0 ; 2) \\
\mathbf{p}<\mathbf{0 . 0 1}\end{array}$ \\
\hline
\end{tabular}

${ }^{1}$ Results presented with Spearman correlation coefficient

${ }^{2}$ Results presented with median and inter-quartile range

$N o$ : nuclear opalescence, $N C$ : nuclear color, $C$ : cortical, $P$ : posterior subcapsular cataracts. 
Table 4: Description of dose-volume characteristics and analysis of dose-volume characteristics as prognostic factors of cataract occurrence according to the LOCS III in bivariate analysis in 42 patients whose crystalline lens was in the proton field

\begin{tabular}{|c|c|c|c|c|c|}
\hline & \multirow[t]{2}{*}{$\begin{array}{l}\text { Volume, \% } \\
\text { (IQR) }\end{array}$} & \multicolumn{4}{|c|}{$\begin{array}{c}\text { Spearman correlation Coefficient }(\mathrm{N}=42) \\
\text { bivariate analysis }\end{array}$} \\
\hline & & NO & $\mathrm{NC}$ & $\mathrm{C}$ & $\mathbf{P}$ \\
\hline $\begin{array}{l}\text { Volume of lens receiving } \\
10 \mathrm{~Gy}\end{array}$ & $18(3 ; 39)$ & $\begin{array}{c}-0.24 \\
\mathrm{p}=0.11\end{array}$ & $\begin{array}{c}0.20 \\
\mathrm{p}=0.18\end{array}$ & $\begin{array}{c}0.19 \\
\mathrm{p}=0.20\end{array}$ & $\begin{array}{c}0.32 \\
\mathbf{p}=\mathbf{0 . 0 3}\end{array}$ \\
\hline $\begin{array}{l}\text { Volume of lens receiving } \\
26 \text { Gy lens }\end{array}$ & $11(0 ; 28)$ & $\begin{array}{c}-0.09 \\
p=0.54\end{array}$ & $\begin{array}{c}0.18 \\
p=0.23\end{array}$ & $\begin{array}{c}0.22 \\
\mathrm{p}=0.15\end{array}$ & $\begin{array}{c}0.33 \\
\mathbf{p}=\mathbf{0 . 0 3}\end{array}$ \\
\hline $\begin{array}{l}\text { Volume of lens receiving } \\
47 \mathrm{~Gy}\end{array}$ & $0(0 ; 10)$ & $\begin{array}{c}-0.21 \\
p=0.17\end{array}$ & $\begin{array}{c}0.28 \\
p=0.07\end{array}$ & $\begin{array}{c}0.17 \\
\mathrm{p}=0.25\end{array}$ & $\begin{array}{c}0.30 \\
\mathbf{p}=\mathbf{0 . 0 4}\end{array}$ \\
\hline $\begin{array}{l}\text { Volume of lens periphery } \\
\text { receiving } 10 \mathrm{~Gy}\end{array}$ & $30(21 ; 40)$ & $\begin{array}{c}-0.28 \\
\mathrm{p}=0.06\end{array}$ & $\begin{array}{c}0.26 \\
\mathrm{p}=0.09\end{array}$ & $\begin{array}{c}0.16 \\
\mathrm{p}=0.28\end{array}$ & $\begin{array}{c}0.35 \\
\mathbf{p}=\mathbf{0 . 0 2}\end{array}$ \\
\hline $\begin{array}{l}\text { Volume of lens periphery } \\
\text { receiving } 26 \mathrm{~Gy}\end{array}$ & $23(11 ; 35)$ & $\begin{array}{c}-0.28 \\
p=0.06\end{array}$ & $\begin{array}{c}0.23 \\
\mathrm{p}=0.12\end{array}$ & $\begin{array}{c}0.14 \\
\mathrm{p}=0.36\end{array}$ & $\begin{array}{c}0.34 \\
\mathbf{p}=\mathbf{0 . 0 2}\end{array}$ \\
\hline $\begin{array}{l}\text { Volume of lens periphery } \\
\text { receiving } 47 \mathrm{~Gy}\end{array}$ & $0(0 ; 25)$ & $\begin{array}{c}-0.21 \\
\mathrm{p}=0.16\end{array}$ & $\begin{array}{c}0.25 \\
\mathrm{p}=0.10\end{array}$ & $\begin{array}{c}0.12 \\
\mathrm{p}=0.41\end{array}$ & $\begin{array}{c}0.21 \\
\mathrm{p}=0.16\end{array}$ \\
\hline $\begin{array}{l}\text { Volume of ciliary body } \\
\text { receiving } 10 \mathrm{~Gy}\end{array}$ & $31(25 ; 38)$ & $\begin{array}{c}-0.24 \\
p=0.08\end{array}$ & $\begin{array}{c}0.30 \\
\mathbf{p}=\mathbf{0 . 0 3}\end{array}$ & $\begin{array}{c}0.19 \\
p=0.16\end{array}$ & $\begin{array}{c}0.30 \\
\mathbf{p}=\mathbf{0 . 0 3}\end{array}$ \\
\hline $\begin{array}{l}\text { Volume of ciliary body } \\
\text { receiving } 26 \mathrm{~Gy}\end{array}$ & $26(21 ; 33)$ & $\begin{array}{l}-0.25 \\
p=0.07\end{array}$ & $\begin{array}{c}0.30 \\
\mathbf{p}=\mathbf{0 . 0 2}\end{array}$ & $\begin{array}{c}0.20 \\
p=0.14\end{array}$ & $\begin{array}{c}0.33 \\
\mathbf{p}=\mathbf{0 . 0 2}\end{array}$ \\
\hline $\begin{array}{l}\text { Volume of ciliary body } \\
\text { receiving } 47 \mathrm{~Gy}\end{array}$ & $15(0 ; 27)$ & $\begin{array}{l}-0.19 \\
p=0.17\end{array}$ & $\begin{array}{c}0.24 \\
p=0.07\end{array}$ & $\begin{array}{c}0.09 \\
\mathrm{p}=0.52\end{array}$ & $\begin{array}{c}0.18 \\
\mathrm{p}=0.17\end{array}$ \\
\hline
\end{tabular}

*The crystalline lens volume receiving $X G y$

$\S$ The crystalline lens periphery volume receiving $X G y$

II The ciliary body volume receiving $X G y$

$I Q R$, inter-quartile range, $N o$ : nuclear opalescence, $N C$ : nuclear color, $C$ : cortical, $P$ : posterior subcapsular cataracts. 